INTER NATIONAL MONETARY FUND
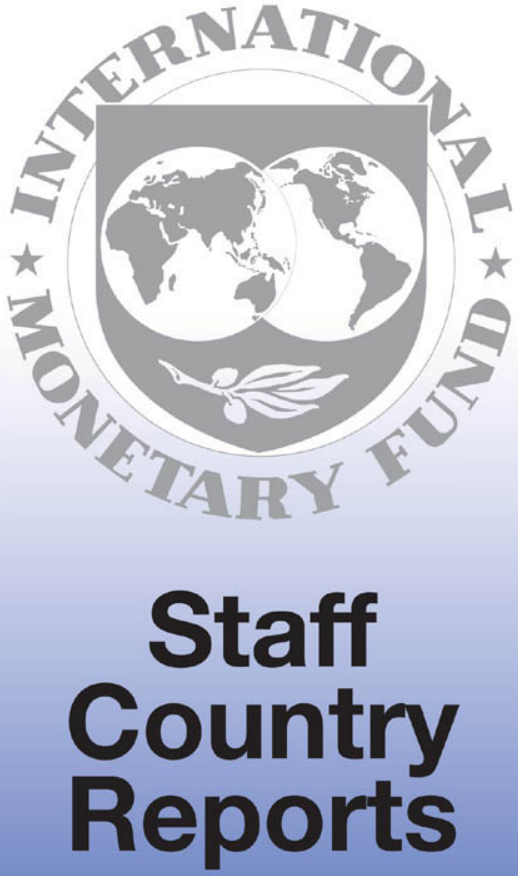


\section{Liberia: Joint Staff Advisory Note of the Poverty Reduction Strategy Paper}

The attached Joint Staff Advisory Note (JSAN) of the Poverty Reduction Strategy Paper for Liberia, prepared jointly by the staffs of the World Bank and the IMF, was distributed with the member country's Poverty Reduction Strategy Paper (PRSP) to the Executive Boards of the two institutions. The objective of the JSAN is to provide focused, frank, and constructive feedback to the country on progress in implementing its Poverty Reduction Strategy (PRS).

Copies of this report are available to the public from

International Monetary Fund $\bullet$ Publication Services

$70019^{\text {th }}$ Street, N.W. • Washington, D.C. 20431

Telephone: (202) 623-7430 • Telefax: (202) 623-7201

E-mail: publications@imf.org • Internet: http://www.imf.org

\section{International Monetary Fund \\ Washington, D.C.}


This page intentionally left blank 


\author{
INTERNATIONAL MONETARY FUND AND \\ INTERNATIONAL DEVELOPMENT ASSOCIATION
}

\title{
REPUBLIC OF LIBERIA
}

Joint Staff Advisory Note on the Poverty Reduction Strategy Paper

Prepared by the Staffs of the International Monetary Fund (IMF)
and the International Development Association (IDA)

Approved by Thomas Krueger and Matthew Fisher (IMF)

and Obiageli K. Ezekwesili (IDA)

June 24, 2008

\section{OVERVIEW}

\section{This Joint Staff Advisory Note (JSAN) reviews the Liberia Poverty Reduction} Strategy Paper (LPRS), covering the period April 2008-June 2011. This first full Poverty Reduction Strategy Paper (PRSP) elaborates on the government's comprehensive strategy for enhancing growth and reducing poverty that was first presented in the government's 150-Day Action Plan (February-June 2006) and the Interim Poverty Reduction Strategy Paper (IPRSP; July 2006-June 2008). The core elements of the LPRS, were broadly endorsed by Liberia's international partners during the February 2007 Partners Forum in Washington D.C.

2. The LPRS was prepared in a participatory manner. Preparation was coordinated by the Liberia Reconstruction and Development Committee (LRDC), chaired by the President, and consisting of representatives of key ministries and international partners, including the IMF and the World Bank. It followed comprehensive consultations with all levels of society that were unprecedented in Liberia's history. It included detailed discussions with Liberians at the district and county level, civil society organizations, the private sector, the legislature, and international partners. Consultations confirmed the four pillars underlying the government's poverty reduction strategy, with high priority being accorded to securing lasting peace, strengthening the judiciary and combating corruption, job creation, and restoring Liberia's infrastructure. To ensure continued strong ownership of and support for the government's reform program, it will now be important to similarly involve all levels of society in monitoring the progress of LPRS implementation. In this regard, the staffs welcome the posting of the LPRS on the Presidential and Finance Ministry websites and the government's plans to prepare an abridged version to facilitate wider distribution, especially to those outside Monrovia. The staffs encourage the government to use a diversity of media outreach to ensure that all segments of the population are covered. 
3. The LPRS comprises a comprehensive strategy to enhance growth and reduce poverty, recognizing that Liberia's history of political instability can be ascribed to the exclusion of Liberians from participation in political governance and limited access to economic assets. It is built on four pillars: (i) consolidating peace and security; (ii) revitalizing the economy; (iii) strengthening governance and the rule of law; and (iv) rehabilitating infrastructure and delivering basic services. The LPRS acknowledges significant capacity constraints in ministries and agencies; it would therefore be important to prioritize policy interventions to ensure key objectives are achieved over the LPRS implementation period.

\section{The LPRS explicitly links policy objectives to the Millennium Development}

Goals, but recognizes that the scope for achieving these goals has been limited by protracted periods of political instability in the 1990s and the first few years of this decade. However, it appropriately sets specific targets that are consistent with making good progress toward the MDGs. The staffs welcome the development of a detailed policy matrix for each of the pillars, and the initial efforts to cost LPRS implementation, but note the importance for a more disaggregated presentation of financing requirements to ensure that own resources and donor support are properly aligned with LRPS policies.

5. This JSAN provides feedback from the staffs of the IMF and IDA on the LPRS. It presents their views on priority areas for strengthening the LPRS as it is implemented.

\section{Poverty Diagnosis}

6. The LPRS gives a clear overview of poverty in Liberia, drawing on data from two new surveys - the Core Welfare Indicator Questionnaire (CWIQ) and the Demographic and Health Survey (DHS) - while recognizing the need to increase the availability of data on poverty and improve its quality. The LPRS recognizes that fourteen years of civil war have transformed Liberia from a relatively wealthy country to one of the poorest countries in the world. Per-capita GDP is estimated at US\$190, some 63.8 percent of the population is below the national poverty line, and 47.9 percent live in extreme poverty. The country suffers from a considerable urban-rural divide, with a poverty incidence of 55 percent in urban areas compared to 68 percent in rural areas, and an extreme poverty incidence of 29 percent in urban areas compared to 56 percent in rural areas.

\section{The LPRS emphasizes both the income and nonincome dimensions of poverty} such as limited access to social services, which has resulted in poor health and limited education. Life expectancy at birth is estimated at 45 years. Preventable diseases, such as malaria, diarrhea, respiratory infections, and measles, are rife. Malnutrition is considered a key factor in high death rates; currently 19 percent of children under 5 are underweight, and 39 percent are stunted. The net primary school enrollment is low ( 37 percent), drop-out rates are high and many children do not proceed to secondary school, as evidenced by low net 
secondary enrolment rates of 15 percent. Enrolment rates are also lower among girls than boys, particularly at the secondary level. In assessing the MDGs, the LPRS candidly recognizes that Liberia is unlikely to reach most of them, in large part due to the legacy of the war. It nevertheless suggests that Liberia can make steady progress in the period to 2015 .

\section{The recently completed poverty diagnosis provides a better understanding of} social conditions in Liberia. However, social data is still very limited and of moderate quality, and must therefore be treated as preliminary. Recent surveys use old sampling frames, and trends are difficult to establish due to poor data quality or variations in the methodology of consecutive surveys. For instance, the infant and child mortality rates reported in the PRSP based on the 2007 DHS are lower than the averages for sub-Saharan Africa and suggest one of the most rapid falls in child mortality ever recorded, in spite of Liberia's extremely high poverty incidence - this raises concerns about data quality.

9. The PRSP highlights the civil war as the underlying cause of extreme poverty. Due to recruitment of people into the armed forces, large population displacement, and general insecurity, the war had a devastating effect on economic activity, and particularly food production. Infrastructure was destroyed, and access to basic services declined. These factors perpetuated poverty by reducing economic opportunities and human capacity. However, the civil conflict was in part a response to rising poverty and inequality, fuelled by a long history of poor governance and a protracted economic crisis throughout the 1980s. In this context, the LPRS poverty diagnostic would have benefited from a longer term historical perspective which focuses on pre-war social conditions and the history of social exclusion that has kept the majority of Liberia's population in poverty, particularly those in rural areas. The fact that the war was driven in large part by the inequalities of the past development path highlights the need for the new development path to be inclusive in sharing the benefits of growth, the provision of services, the ownership of assets and the distribution of public resources.

\section{The growth ANd Poverty Reduction AgendA}

\section{A. Macroeconomic Framework}

10. The LPRS appropriately emphasizes the critical importance of a stable economy if rapid, inclusive and sustainable economic growth is to be achieved. The macroeconomic framework underlying the LPRS is consistent with the authorities' PRGFsupported policies. The authorities target average annual real GDP growth of about 12 percent in the next four years, bringing inflation down to single digit levels, and maintaining relative exchange rate stability. While the staffs agree there could be a significant acceleration in real GDP growth over the medium term as resource-based activities resume, data should be interpreted with caution. Liberia's statistical capacity was severely damaged during the civil wars, and the last official estimates of real GDP were produced in 1988. It 
will therefore be important to put in place the national statistical development strategy that is currently being prepared; the first annual progress report (APR) of the PRS should describe progress in resuming the collection and dissemination of economic statistics.

11. The costing of the LPRS identifies significant financing gaps. Under its current policy framework, the government is committed to a balanced budget, and the bulk of LPRS financing is expected to be provided by donors. On average, Liberia's own resources are expected to cover about one-third of LPRS costs. With almost all donor support currently disbursed outside the government budget, it will be important to strengthen the donor coordination through the LRDC, including gathering detailed data on donor activities, to ensure that donor support is aligned with the LPRS priorities. In this context, presenting a detailed costing of LPRS policies and actions would be useful. Prioritizing LPRS policies would also be important for scaling back actions if sufficient financing is not available. The staffs take note of the government's intention to mobilize private sources of financing, such as concession agreements and public-private partnerships, but urge careful consideration of the terms of such arrangements to ensure that contingent fiscal liabilities are properly identified and assessed within the context of the government's debt management strategy that is currently under preparation, and its debt management capacity.

\section{The LPRS sets out an ambitious medium-term program for further}

strengthening public revenues. However, it will be important to ensure that the program is consistent with implementation capacity and specifies clear responsibility and processes to manage and deliver the reform program effectively. While public expenditure management (PEM) has also been improved, including through eliminating the accumulation of new domestic payments arrears and finalizing a domestic debt resolution strategy, budget implementation has been less strong. Expenditures have continued to lag behind available cash resources, leading to pressures toward the end of the fiscal year, including for transfers between budget lines. It would therefore be important that the first APR assess progress in strengthening budget implementation. In addition, the staffs note the importance of developing a system for tracking LPRS-related expenditures. The LPRS notes that a comprehensive public financial management (PFM) law is being drafted to further strengthen budget preparation, implementation and reporting. The APR should report on the elements of the new PFM system, including details and timetable for the implementation of the new PEM system that is intended to replace the current interim commitment control system. Strong implementation of a sound PFM system should encourage a much-needed shift of donor assistance to budget support.

\section{The LPRS reports on progress in addressing Liberia's unsustainable external}

debt. The staffs welcome the government's commitment not to engage in new external borrowing until Liberia's unsustainable debt burden has been resolved, a comprehensive debt strategy has been developed, and institutional debt management capacity has been established. The staffs note the importance of continuing discussions with private creditors in 
order to ensure their participation in the Enhanced HIPC Initiative. Continued strong progress under the PRGF-supported program and achieving the floating completion point triggers would be critical in receiving debt forgiveness. The staffs also stress the importance of continued implementation of the government's domestic debt strategy, including establishment of a trust fund to ensure sufficient resources for its implementation.

\section{The LPRS notes the goal of empowering counties and districts by devolving to} them powers and functions, including fiscal functions. It would be helpful for the APR to discuss current experience with implementing county and community development funds, which are disbursed as lump sums to counties, and require ex post detailed reporting on implementation. Furthermore, it would be important to elaborate on the modalities of, and schedule for, the proposed fiscal decentralization. Establishing strong institutions and capacity at the national level, and setting a realistic goal for fiscal decentralization, would be critical to ensure that current efforts to strengthen public financial management are not weakened.

15. The LPRS acknowledges the challenges associated with implementing monetary policy in a highly dollarized economy. The staffs agree that the Liberian dollar/U.S. dollar exchange rate is an important indicator of imbalances between Liberian dollar supply and demand. In this context, the staffs agree that targeting exchange rate stability is appropriate. Since the LPRS states that the authorities will continue to strengthen policy tools for managing Liberian dollar liquidity, it would be useful for the APR to elaborate on these initiatives. The LPRS also notes that the authorities will consider policy options regarding the dual currency system; in this regard, the staffs stress the importance of carefully assessing the potential benefits and costs before considering the adoption of a different currency regime.

\section{B. Security and Conflict}

16. The poverty reduction strategy recognizes that peace and security are major preconditions for sustainable growth. The peace and security pillar of the LPRS accounts for the second largest share of the budget, after infrastructure and basic services. The staffs agree that the emphasis on peace and security is vital for building domestic and international investor confidence in Liberia. Increased confidence in Liberia's security situation will not only be critical for spurring new investment but will also enhance the government's ability to negotiate down the premiums attached to country risk. The LPRS also acknowledges that the unresolved issues with respect to land tenure could be sources of future conflict. In this regard, staffs would encourage the government to expedite the passage of proposed legislation for the establishment of the independent Land Commission in order to begin settling some of the fundamental issues regarding rights in land and land-based resources.

17. Devoting resources and attention to national security institutions will become increasingly critical as the UN draws down its peacekeeping force. Against this 
background, the staffs note that the assumed budget allocation to peace and security will gradually fall over the three years of the LPRS. A more detailed costing of LPRS policies (see para. 11) would help to assess the realism of scaling-down budget allocations for this key pillar.

\section{Structural Policies for Growth and Investment}

\section{The growth strategy presented in the LPRS consists of three elements: (i)} rebuilding basic infrastructure; (ii) restoring production in the resource-based sectors; and (iii) establishing an environment to promote economic diversification. The level of resources devoted to basic infrastructure in the LPRS suggests that this is a major priority area for the government. This is also an area where it has made notable progress so far. However, significant amounts of resources are still required to rebuild roads, and provide electricity and water. A major challenge for the government is therefore to attract more donor aid and private investment in the provision of infrastructure given it own limited budget and the constraints on borrowing. The staffs agree that it is appropriate in the short to medium term to focus on supporting the restoration of traditional sources of growth, such as agriculture, forestry and mining, while also establishing an environment that in the longer run will support economic diversification. However, given that most of the poor are in the rural areas and are engaged in agriculture, there is need for greater specificity in the articulation of the plans for agriculture. For example, there is need for greater clarity on the plans to rebuild research and development and the extension service capacities within agriculture. The link between pro-poor growth and human resource development, including education and training, could also be better elaborated in the LPRS.

\section{Agriculture, forestry, and mining are expected to be the main sources of growth} in the medium term. The LPRS places heavy emphasis on activities to improve productivity in the agricultural sector, where the largest proportion of the population is employed, and which thus has the most scope for reducing poverty. Current estimates point to a significant impact on poverty incidence of rising world food prices, and improving food security by increasing domestic food production is therefore especially critical as global food prices increase while Liberia remains heavily import-dependent. The staffs welcome that the government's response to current high world food prices, focusing on increasing domestic food production, is consistent with the LPRS policies and actions. Since the lifting of sanctions on timber in 2006, the authorities have made excellent progress in the forestry sector with the building of institutions to ensure that logging is sustainable. The staffs would like to encourage the authorities to continue their measured approach to logging to ensure that Liberia's forests are preserved, and stay open to alternative opportunities for revenue generation, such as eco services, particularly carbon credit schemes.

20. Although the growth measures proposed under the LPRS may have a meaningful employment impact in the long-term, they are unlikely to absorb a 
significant number of the unemployed in Liberia to lift them out of poverty in the shortterm. Staffs therefore commend the Government's efforts towards targeted social safety net programs (including carefully planned and executed labor-intensive projects) to mitigate the impact of shocks (such as the recent food price crisis) on the most vulnerable.

\section{The LPRS proposes a number of structural policies to facilitate the expansion} and functioning of markets and to establish a regulatory environment that is conducive to long-term growth. The government has already made progress on some key structural policies, including on governance, with the anti-corruption strategy, the launching of the Liberia Extractive Industries Transparency Initiative (LEITI) and the rebuilding of roads. During the LPRS period the government plans to abolish all statutory monopolies, draft a national mining sector framework, and formulate a land policy. While the comprehensive structural reform agenda outlined in the LPRS is welcome, the staffs note that it is ambitious and the government may need to set policy priorities that better reflect its implementation capacity.

22. The LPRS emphasizes the importance of an efficient financial sector for raising economic growth and reducing poverty. The government's strategy for financial sector development appropriately focuses on promoting a stable, sound, and market-based system that can support the efficient mobilization and allocation of domestic savings. The APR should therefore provide details of (i) the elements of the new Liberian national payments system; (ii) the national microfinance policy; (iii) measures to broaden access to finance; and (iv) efforts to strengthen banking regulations and supervision to ensure financial sector stability.

\section{Governance and the Rule of Law}

23. The LPRS identifies poor governance and an ineffective legal system as root causes of political and social unrest in Liberia. It lays out ambitious objectives to enhance public participation in governance, make public institutions more effective, and increase access to the legal system. The LPRS cites efforts already underway to reform governance, such as plans to establish Anti-Corruption, Law Reform, and Land Commissions, drafting a Code of Conduct for public servants, and addressing gender equity and reducing violence against women. Staffs commend these efforts and would also encourage efforts for the increased involvement of civil society in monitoring and ensuring accountability in the sustainable use of land and marine natural resources.

24. The staffs welcome the government's intentions to work in partnership with citizens to build and operate effective institutions and systems that will entrench peace and promote and uphold democratic governance, accountability and justice. The intensive consultations the government held in preparing the LPRS are a clear demonstration of its objectives of enhancing citizen participation in and ownership of government policies 
and actions. In addition, the government has made an ambitious commitment to decentralize power, decision making, and authority in order to improve governance, increase transparency, enhance accountability, and improve the delivery of services.

25. The government has taken important steps to reduce corruption. It has adopted a strong national anticorruption policy and strategic framework. Going forward, the staffs recommend that the establishment and empowerment of the Anti-Corruption Commission be expedited so that prosecution of corruption cases can begin. It will also be important to ensure that the Commission is fully financed and staffed.

26. The government has made a strong commitment to gender equality as a means of maintaining peace, reducing poverty, enhancing justice and promoting development. However, because progress on drafting the gender policy and the implementation strategy has been slow, the government's strategic position on gender issues has not advanced much beyond what was expressed in the I-PRSP. For example, it is not clear what legal reforms may be required to give effect to measures to better protect women and address major gender inequities.

27. The LPRS has set out an extremely ambitious policy and legislative agenda to make public institutions and functionaries more effective. This agenda can only be achieved with strong dialogue and collaboration between the legislative and executive branch of government. Improving the effectiveness of public institutions is a critical objective of governance reform to ensure that the state can efficiently and credibly deliver services to ensure that poverty is reduced. The most notable progress is on civil service reform, where the government has articulated its commitment to politically sensitive measures, such as right-sizing, performance-based management, pay reform and pension reform. The actions identified in the LPRS focus on the completion of strategy documents on public institutional reform, civil service reform, decentralization, and legal reform. The staffs urge the government to focus on the critical steps that will be required to effect change. The staffs would also encourage greater focus on the refinement and prioritization of the specific interventions to strengthen the legal system and expand access to justice.

\section{E. Cross-cutting Issues}

\section{The identification of six cross-cutting themes in addition to its four pillars} enhances the comprehensiveness of the LPRS. These are gender equity, peace-building, environmental issues, HIV and AIDS, children and youth, and monitoring and evaluation. These themes are certainly appropriate for Liberia. However, managing the six working groups concerned with the cross-cutting themes and the four working groups concerned with the pillars is a formidable task in institutional coordination for an administration with limited capacity. As a practical matter, it may be necessary to collapse the membership of some of 
these working groups. For example, the Gender and Equity and the Children and Youth working groups might have the same constituents.

\section{MONITORING OF PRSP IMPLEMENTATION AND PRSP IMPLEMENTATION RISKS}

29. The LPRS specifies an elaborate institutional framework for monitoring PRSP implementation and evaluating outcomes. The staffs welcome both the allocation of primary responsibility for managing the monitoring and evaluation (M\&E) system to the LRDC and the specification of objectives for strengthening the institutional framework underlying the M\&E system. However, given limited capacity and the lack of good statistics, priority should be given to establishing a well-functioning system at the national level before designing a system for producing and disseminating county and district data. It will also be important to clarify the role of the legislature, CSOs, the private sector, and Liberian citizens in monitoring implementation and evaluating outcomes. In the building of the county-level M\&E structures, staffs would encourage the government to move in the direction of piloting the use of social accountability mechanisms, including possibly the use of community scorecards to track progress on the delivery of a range of public services including infrastructure, judicial, health and education.

\section{While the proposed M\&E system identifies sources of data for monitoring} progress on the four pillars, it does not address the lack of sound data on most economic and social variables. It would therefore be useful to discuss the main elements and objectives of the national statistical development strategy, currently under preparation, in the first APR. Specifically, it would be useful to describe the schedule for resuming production of data for important economic sectors, such as agriculture, mining, manufacturing, and services. The LPRS also elaborates a number of specific targets for each pillar, but it is not clear that outcomes in all cases are directly related to specific policies. The staffs therefore note the importance of aligning LPRS goals and targets with policy objectives.

\section{The main risks to achieving LPRS goals pertain to capacity constraints and}

financing requirements. However, there are several inherent country risks including political, security, corruption, and vulnerability to external shocks which could also impact implementation of the PRS. While some progress has been made in building capacity, there are still significant problems at middle and lower levels in government. It will therefore be important to ensure that donor-funded experts, for example, those in the Governance and Economic Management Assistance Program, also work to build local capacity and to fully implement the comprehensive civil service reform strategy that is currently being finalized. A major risk to LPRS implementation stems from its significant financing needs, and the fact that most donor assistance is currently provided outside the government budget. This emphasizes the need for strong donor coordination to ensure that support is aligned with LPRS priorities, as well as the need to strengthen PFM to support a move toward higher 
budget support. Timely implementation of HIPC completion point triggers will also limit the risk of delays in obtaining financing for the LPRS. In terms of the political risks, a number of policies require legislative action, and it would be important for the government to ensure continued discussion with the legislature to ensure that key actions are undertaken in a timely manner. While Liberia has enjoyed almost five years of peace and stability, the risk of renewed conflict is still high and hence while building capacity in security forces therefore remains a key priority, the pro-poor interventions are equally important. Liberia is also highly vulnerable to external shocks, notably fluctuations in the prices of its main exports and volatility in food and fuel prices.

\section{CONClusion ANd Issues For Discussion by EXeCuTIVe DiRectors}

32. The LPRS presents a comprehensive, credible medium-term strategy to improve socioeconomic indicators and reduce poverty consistent with the rates of change underlying the MDGs. However, the PRS lacks specificity on the short-term strategy for preserving social stability and peace until the benefits of the medium-term strategy are widely felt. Looking forward, the staffs note a number of areas for immediate action and a number of issues which could be further elaborated in the first APR, including: (i) developing a detailed and prioritized costing of LPRS actions and policies; (ii) providing greater specificity of the strategy for pro-poor growth and particularly on the plans for the development of domestic agriculture; (iii) expediting the law to establish the Land Commission; (iv) discussion of the elements of the PFM system currently being finalized; (v) elaborating government's strategy and timetable for devolving political and financial authority to lower levels of government; (vi) elaborating measures (including piloting social accountability systems) to ensure broad involvement in monitoring and evaluating LPRS implementation; and (vii) detailing the elements of the national statistical development strategy and a timetable for improving collection and dissemination of economic statistics.

\section{In consideration of the LPRS and associated JSAN, Executive Directors' views} are sought on whether they agree with the main areas identify by staffs as priorities for strengthening the strategy and its implementation, and areas identified as key implementation risks. 